\title{
BIOMASS ADAPTATION TO POWER IN INDIA - AN ASSESSMENT
}

\author{
P. Rathna \\ Research Scholar \\ Department of Management Studies \\ Bharath Institute of Higher Education and Research, \\ Chennai-600073, Tamil Nadu, India
}

\begin{abstract}
This paper fundamentally examines the degree, potential and execution of biomass change to vitality in Indian situation. The plausibility just as appropriateness of the different classifications of biomass to vitality in India has been talked about. Brief depictions of potential transformation courses have been incorporated with their conceivable and existing extent of usage in Indian setting, beyond what many would consider possible, the latest factual information have been accounted for from the accessible sources. The discourse uncovers that a huge potential exists for the biomass feed-stocks from the different sorts of waste biomass. The gasification just as anaerobic assimilation forms is by all accounts most alluring in Indian situation.
\end{abstract}

Keywords-Biomass Sun based vitality, Wind Vitality and Hydropower.

\section{INTRODUCTION}

India is a quick creating nation which is accomplishing consistent upward modern development in recent decades. Similarly, its business vitality utilization is additionally developing with a similar pace of high monetary development and mechanical improvement. The significant sources which meet the vitality prerequisite of India are coal and oil. The essential vitality utilization amid 2008 is accounted for to be: coal-53.4\%; oil-31.2\%; gaseous petrol-8.6\%; hydroelectricity $-6.0 \%$; and atomic vitality $-0.8 \%$. The local part utilization of vitality is fundamentally coal and lamp oil. The utilization of these energizes isn't just dangerous because of outflow of green house gases; these are likewise quick exhausting wellsprings of vitality. Besides India is subject to the imports for oil necessities. In 2004- 05, 72\% of India's complete oil utilization was subject to the imports. This figure came to $76.5 \%$ amid $2006-07,78 \%$ for $2007-08$, and the conditional figure for $2008-09$ is $79.3 \%$. The major sustainable wellsprings of vitality accessible unreservedly are sun based vitality, wind vitality, little hydropower, biomass, biogas, and vitality recuperation from civil and mechanical squanders. India is a nation which is wealthy in normal assets. A large number of these assets have an incredible potential for misuse in India. Sustainable sources have preferred standpoint

\author{
Dr. A. Ravikumar \\ Research Supervisor \& Associate Professor \\ Department of Management Studies \\ Bharath Institute of Higher Education and Research, \\ Chennai-600073, Tamil Nadu, India
}

of complete ceaselessness; simple neighbourhood accessibility with no requirement for real transport, along these lines less green house gases discharge in condition; measured quality, for example economy is free of scale; and non-dirtying in nature. The first since forever endeavour to misuse sustainable power source in India goes back to 1897 when a little hydropower venture of $130 \mathrm{~kW}$ limits was actualized at Sidrapong in Darjeeling. This was trailed by two more hydro undertakings of 40 and $50 \mathrm{~kW}$ limits individually, each introduced at Chamba (1902) and Jubaal (1911).

In the previous decade there has been restored enthusiasm for the biomass as a sustainable power source around the world. The real explanations behind this are as per the following. As a matter of first importance innovative treatments identifying with the transformation, crop generation, and so on guarantee the use of biomass at lower cost and with higher change proficiency than was conceivable beforehand. The potential risk presented by environmental change, because of high outflow dimensions of ozone depleting substances, the most imperative being $\mathrm{CO} 2$, has turned into a noteworthy boost for sustainable power sources when all is said in done. At the point when delivered by support capable methods, biomass transmits generally indistinguishable measure of carbon amid transformation from is taken up amid plant development. The utilization of biomass in this manner does not add to a development of $\mathrm{CO} 2$ in the environment.

The present paper shows a basic examination of the potential and extent of the bio vitality creation and execution in Indian situation. Here we have endeavoured to break down the present day circumstance in the light of accessible statistical data points in the open writing. A short depiction of the procedures for change of distinguished biomass feedstock to vitality and fills has likewise been incorporated. Beyond what many would consider possible, biomass accessibility and utilization insights has been refreshed to the most recent figures accessible till date.

\section{Practicality of Biomass Vitality Change}

Disregarding numerous apparent advantages, the possibility of the biomass vitality change particularly as far as GHG outflows is as yet easily proven wrong. Avis has ordered the bio-vitality assets into two principle classes. One is agro- 


\section{International Journal of Engineering Applied Sciences and Technology, 2019 Vol. 4, Issue 6, ISSN No. 2455-2143, Pages 57-65 \\ Published Online October 2019 in IJEAST (http://www.ijeast.com)}

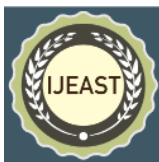

powers and other bio-energizes. Bio-fills are biomassdetermined energizes intended to supplant oil and utilized for the most part in the vehicle segment. In spite of the fact that the words "bio-fuel" and "agro-fuel" are regularly utilized conversely, he underscores to separate the two so as to have better appraisals of their effect on nature just as monetary examination. An agro-fuel, is a kind of bio-fuel, comprising of yields and additionally trees developed on a huge scale (for example monoculture). Models incorporate fuel yields, for example, maize, corn, rice and wheat. Bio-powers got from waste, for example, biogas from fertilizer or landfill, or waste vegetable oil are not agro-powers. Ethanol and bio-diesel are likely the most outstanding types of agro-fills for fuel and diesel substitution separately. They have been utilized for a long time in a few sections of the world.

\subsection{Natural elements}

The International Panel on Climate Change (IPCC) rules, and the World Resources Climate Analysis Data, the survey delivered an intriguing pie-diagram (Fig. 1), demonstrating the GHG outflows by hotspot for the year 2000. It is clear from this outline $35 \%$ of discharges are from farming and changes in land-use. The land-use change is the second biggest wellspring of outflows (18\%), after the power part $(24 \%)$. Further, it is obvious that horticulture outflows are equivalent (14\%) and land-use change discharges are more noteworthy (18\%) than the commitment from transport.

The wellspring of horticulture discharges, because of serious cultivating is nitrogen manure creation/use and outflows of nitrous oxide (NO2) from the field. In view of the exceptionally amazing GHG impact of nitrous oxide (multiple times that of $\mathrm{CO} 2$ ) even generally little outflows can significantly affect the general GHG balance. Subsequently the decrease in GHG outflows essentially relies upon various things. Above all else, factors, for example, yield, atmosphere, soil type, and ground spread and development strategy suspicions have a vast effect on assessed discharges. Furthermore, base case presumptions, for example, the first land-use and whether deforestation jump out at account for the fuel crop. Third critical factor is procedure to make the fuel. On account of ethanol generation, the utilization of cogeneration with a gas-terminated turbine over customary creation plans has been professed to diminish GHG outflows by $45 \%$ [8]. In any case, utilizing coal would clear out the GHG reserve funds when contrasted with fuel. Side-effect use is another essential factor. It has any kind of effect if the sideeffects of the refining procedure utilized as creature feed or for fuel. The most minimal by and large GHG discharges (up to $80 \%$ decrease over petroleum products) are achievable when bio-diesel is produced using waste cooking oil or methane from fluid compost.

In perspective on the over the execution of bio-energizes in any nation, the natural effect is the main consideration to be considered before we consider the abuse of bio-vitality. As referenced in the last section, the land-use change is the significant supporter of the GHG outflows. These contemplations are essential at the season of making life cycle evaluation of any bio-vitality age process.

\subsection{Financial components}

The Bio vitality Wiki contains data on inexhaustible fuel focuses for different nations. As per it, India focus to accomplish 5\% in ethanol in specific states and 20\% bio-diesel constantly 2012. In any case, the revealed truth on the encounters of Chattisgarh State is that 400 million Jatropha saplings were planted on in excess of 155,000 ha of neglected land over the most recent 3 years. Be that as it may, until year's end 2008, there has been no detailed information on survival of saplings or seed creation. Agriculturists in numerous territories are in a fix as the trees have not yet borne natural products, while in spots where they have, different divisions and neighbourhood offices, and are hanging tight for rules on accumulation and clearance of seeds. Essentially, a 2006 investigation by the UN Conference on Trade and Development (UNCTAD) inferred that India can't depend on sugarcane molasses as a solid feedstock for liquor, given the harvest's reliance on storm and fancies of the residential sugar industry. So also, challenges in obtaining oilseeds and absence of framework could discourage generous bio-diesel generation by $2011-12$.

While considering the usage of agro-powers, the social effects are likewise vital and can't be ignored because of numerous reasons. During the time spent executing bioenergizes, especially agro-fills, we have to guarantee that the land just as assets, we are dispensing to the reaping of these yields don't meddle the sustenance crops segment. Also in this procedure we make a portion of the agriculturists jobless. In a nation like India horticulture is a standout amongst the most imperative divisions of its economy. It is the methods for business of just about $66 \%$ of the work compel in the nation and as per the monetary information for the money related year 2006- 07, horticulture represents $18 \%$ of India's GDP. About $43 \%$ of India's geological territory is utilized for horticultural action. In spite of the fact that the offer of Indian horticulture in the GDP has relentlessly declined, it is as yet the single biggest supporter of the GDP and assumes an essential job in the general financial improvement of India. The poor agriculturists gain their job, yet the sustenance for their family is additionally originating from their harvests.

\section{POTENTIAL BIOMASS ACCESSIBILITY IN INDIA}

Biomass, characterized as all land and water-based vegetation just as natural squanders, satisfied practically all of mankind's vitality need before the modern unrest. In present day situation, by and by its usage for age of vitality has picked up force due to constrained accessibility of the customary vitality assets just as ecological worry due to GHG discharges. Analysts describe the different kinds of biomass in various 


\section{International Journal of Engineering Applied Sciences and Technology, 2019 Vol. 4, Issue 6, ISSN No. 2455-2143, Pages 57-65 \\ Published Online October 2019 in IJEAST (http://www.ijeast.com)}

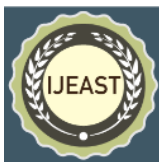

ways however one straightforward arrangement is as per the following. The principle kinds of biomass are woody plants, herbaceous plants or grasses/bushes, oceanic plants, and composts. Late green growth has additionally been distinguished as a potential wellspring of bio-diesel. Fundamentally there are three unmistakable wellsprings of biomass vitality: vitality manors, rural harvest build-up and city and mechanical squanders. A short portrayal pretty much this has been given in the accompanying subsections.

\subsection{Horticultural feed-stocks — vitality crops}

An extensive populace in India is reliant on agribusiness as their vocation. In perspective on this a huge populace of cows and animals additionally exists in India. In this way the capability of different sorts of biomass accessibility exists in Indian towns. Harvests that have been utilized for vitality include: sugarcane, corn, sugar beets, grains and numerous others. There are a few variables, which decide if a yield is appropriate for vitality use. The fundamental material properties of enthusiasm amid resulting handling as a vitality source, identify with-dampness content (characteristic and outward), calorific esteem, extents of settled carbon and volatiles, cinder/build-up content, soluble base metal substance, and cellulose/lignin proportion. The initial five properties are noteworthy for dry biomass change forms, while first and last properties are vital for wet biomass transformation. Great vitality crops have a high return of dry material per unit of land (dry ton/ha). Various creators have likewise assessed the potential land for developing biomass in India.

\subsection{Agribusiness crop deposits}

A lot of agribusiness deposits are delivered in horticulture based nation like India. These comprise a potential biomass feedstock for vitality transformation. The term agrarian buildup is utilized to portray all the natural materials which are created as the results from collecting and preparing of farming yields. These build-ups can be additionally classified into essential deposits and optional deposits. Farming build-ups, which are created in the field at the season of gather are characterized as essential or field based deposits (for example rice straw, sugar stick tops), though those co-created amid preparing are called optional or handling based build-ups (for example rice husk and bagasse). Accessibility of essential build-ups for vitality application is normally low since gathering is troublesome and they have different uses as compost, creature feed, and so on. Anyway optional deposits are normally accessible in generally substantial amounts at the preparing site and might be utilized as hostage vitality hotspot for a similar handling plant including no or little transportation and taking care of expense. This table records the potential Indian harvests creating deposits and their accessible amount.

\subsection{Biomass squanders - a potential feedstock for anaerobic assimilation}

An immense amount of different biomass squanders are created in creating nations like India. These squanders can be changed over to the vitality energizes by bio-synthetic just as thermo-concoction transformation courses. The potential biomass squanders recognized and utilized for bio-vitality generation in India are recorded in the consequent subsection. A large number of these squanders are by and large effectively used in different bio vitality applications the nation over.

\subsubsection{Agro-industry squanders and verdant biomass}

Aside from the deposits from the rural homesteads and fields in urban territories certain different build-ups and squanders additionally comprise a potential wellspring of the vitality. The agro handling enterprises, urban vegetable commercial centres, street sweepings and street side estates are a few territories which produce noteworthy biomass squander. The administration of these zones is by and large in the hands of poor ranchers and the disorderly division, rustic families and the low pay little agro based industry segment. An ongoing report demonstrates that very nearly 200 million tons of family unit and agro preparing squanders are produced yearly in India and arranged in a scattered way. Since they are related with practically no creation costs they are either unused or used wastefully. A lot of verdant squanders are singed bringing about air contamination.

\subsubsection{Wastewaters and mechanical squanders}

Effluents and different squanders make issues of water and soil contamination. Dumping has genuine results. Amid the procedure of natural decay of these losses ashore, natural issue permeates into the ground water or keeps running off to surface waters causing contamination which prompts wellbeing dangers and fish mortality. These are squander effluents from the ventures, for example, dark alcohol from mash and paper industry, wastewater from slaughterhouse, milk preparing units, bottling works, vegetable bundling industry, and creature fertilizer. The wastewater creation figures in India and run of the mill COD have been taken from the different sources in writing. The vitality generation potential may rely on the reactor being utilized and reactor productivity, however these squanders can adequately be utilized as feedstock for the bio-fuel creation. The biogas creation potential has been accounted for by different creators in the scope of $0.15-0.45 \mathrm{~m} 3 \mathrm{CH} 4 / \mathrm{kg}$ of COD evacuated [42]. The figures revealed for vitality potential in this table are determined on a premise of a normal estimation of $0.3 \mathrm{~m} 3$ $\mathrm{CH} 4 / \mathrm{kg}$.

\subsubsection{Sustenance industry squanders}

The inn, eateries and network kitchens produce a great deal of waste, for example, vegetable strips, uneaten sustenance for example rice, bread, vegetables, meat, and so forth., plate and dish washings, foods grown from the ground rejects. Correspondingly, a colossal measure of squanders is created from confectionary industry. 


\section{International Journal of Engineering Applied Sciences and Technology, 2019 Vol. 4, Issue 6, ISSN No. 2455-2143, Pages 57-65 \\ Published Online October 2019 in IJEAST (http://www.ijeast.com)}

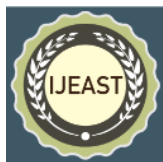

Strong squanders from these businesses incorporate peelings and scraps from leafy foods, sustenance that does not satisfy quality control guidelines, mash and fibre from sugar and starch extraction, channel sledges and espresso beans. Every one of these squanders makes a potential feedstock for biogas age by anaerobic absorption. These squanders are typically arranged off in landfill dumps.

Fluid squanders are created by washing meat, foods grown from the ground, whitening products of the soil, pre-cooking meats, poultry and fish, cleaning and preparing activities and wine making. These wastewaters contain sugars, starches and other broke down and strong natural issue. The potential exists for these modern squanders to be a vigorously processed to create biogas, or matured to deliver ethanol. A few business instances of waste-to-vitality transformation as of now exist utilizing these feed-stocks.

\subsubsection{Creature squanders}

Creature fertilizer is basically made out of natural material, dampness and powder. Deterioration of creature excrement can happen either in a vigorous or anaerobic condition. Under oxygen consuming conditions, $\mathrm{CO} 2$ and balanced out natural materials (SOM) are delivered [44]. Under anaerobic conditions, $\mathrm{CH} 4, \mathrm{CO} 2$, and SOM are created. Since the amount of creature compost delivered every year can be generous for a nation like India, the potential for $\mathrm{CH} 4$ generation and consequently vitality capability of creature excrement is huge.

\subsubsection{Metropolitan strong waste}

A huge number of huge amounts of family unit squander are gathered every year with most by far arranged off in open fields. The biomass asset in MSW involves the paper and plastic and midpoints $80 \%$ of the all out MSW gathered. Civil strong waste can be changed over into vitality by direct ignition, or by common anaerobic processing in the built landfill.

On the landfill destinations the gas created by the common deterioration of MSW (roughly half methane and half carbon dioxide) is gathered from the put away material and scoured and cleaned before sustaining into interior ignition motors or gas turbines to produce warmth and power. The natural portion of MSW can be a vigorously balanced out in a highrate digester to get biogas for power or steam age.

Sewage is a wellspring of biomass vitality that is fundamentally the same as the other creature squanders. Vitality can be removed from sewage utilizing anaerobic processing to deliver biogas. The sewage ooze that remaining parts can be burned or experience pyrolysis to create more biogas.

This unmistakably delineates the gigantic capability of transformation of different biomass squanders to vitality, in Indian situation. A large number of these advancements have gainfully been executed and are being utilized by businesses by in-house vitality sparing, and consequently signifying their benefits. These advancements are being adjusted by comparative businesses with the assistance of different government offices for example MNRE (some time ago known as MNES), scholarly establishments like Indian Institute of Science (IISc) and Indian Institutes of Technology (IITs), just as certain non-government associations.

The above talk and assembled information unmistakably infers that vast extension exists for the abuse of bio-crops for their transformation to bio-energizes for example ethanol and bio-diesel, by thermo change just as bio-substance transformation courses. Aside from these vitality crops, a gigantic potential exists for vitality age from the different modern wastewaters by bio-concoction courses. Thus different biomass squanders for example wood squanders, crop deposits, creature fertilizers, and civil squanders likewise bear an extensive potential for vitality age utilizing bio-synthetic just as thermo-compound courses. Accordingly biomass transformation to vitality and fills might be a very remunerating in Indian situation.

\section{Methods FOR BIOMASS CHANGE To IMPERATIVENESS}

It is obvious from the above talk that an arrangement of feedstocks is available for abuse for change to the bio-controls similarly with respect to control age applications. In context on this a variety of systems exists for biomass changes. The most used of these are warm changes, bio-blend and manufactured changes and direct consuming. The warm change shapes include snappy and moderate paralyses and biomass gasification; the bio-compound change is development and anaerobic ingestion; blend changes are trancesterification and diverse systems to change over plant and vegetable oils to bio-diesel, and direct consuming of wood and distinctive biomass is being used for a very long. This subsection shows an essential review of these known systems in Indian situation.4.1. Warm transformation formsliquefaction, paralysis and gasification

The primary warm transformation forms known for biomass change are liquefaction, moderate and quick paralysis, and gasification. The substance synthesis of biomass is altogether different from that of coal oil, oil shale, and so on. The nearness of a lot of oxygen in plant starch polymers implies the paralytic science contrasts forcefully from these other fossil feeds. Wood and other plant biomass is basically a composite material constructed from oxygen-containing natural polymers. The plant biomasses basically comprise of low sub-atomic weight natural extractives and inorganic minerals (for the most part 4-10\%), and Macro-particles like polysaccharides for example cellulose and polyoses (generally 65-75\%) and lignin (around 18-35\%) [45]. The species experiencing compound change amid warm transformation are cellulose, hemi-celluloses, and lignin. The wt percent of these segments fluctuate in various assortments of woody biomass. Different biomass bolsters change to bio-oil and roast to 


\section{International Journal of Engineering Applied Sciences and Technology, 2019 Vol. 4, Issue 6, ISSN No. 2455-2143, Pages 57-65 \\ Published Online October 2019 in IJEAST (http://www.ijeast.com)}

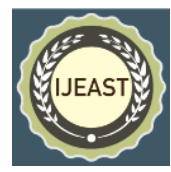

different degrees, contingent on their substance synthesis just as dampness substance. Paralysis is the major substance response process that is the antecedent of both the gasification and ignition of strong energizes. In straightforward terms paralysis is characterized as the concoction changes happening when heat is connected to a material without oxygen. Burning of biomass for use in inner ignition motors for power age gives an imperative interchange sustainable power source asset. Gasification is halfway ignition of biomass to deliver gas and burn at the principal organize and resulting decrease of the item gases, essentially $\mathrm{CO} 2$ and $\mathrm{H} 2 \mathrm{O}$, by the charcoal into $\mathrm{CO}$ and $\mathrm{H} 2$. The procedure likewise produces some methane and other higher hydrocarbons relying upon the plan and working states of the reactor. Different paralysis forms have been quickly depicted in the accompanying subsections.

As referenced above, regular paralysis is characterized as the paralysis, which happens under a moderate warming rate. This condition allows the generation of strong, fluid, and vaporous paralysis items in critical bits. Traditional moderate paralysis has been connected for a huge number of years and has been basically utilized for the creation of charcoal. The warming rate in ordinary paralysis is ordinarily much slower than that utilized in quick paralysis. A feedstock can be held at consistent temperature or gradually warmed. Vapors can be constantly expelled as they are framed.

Moderate pyrolysis of biomass is related with high charcoal mainland, yet the quick pyrolysis is related with tar, at low temperature $(675-775 \mathrm{~K})$, or potentially gas, at high temperature. At present, the favored innovation is quick or blaze pyrolysis at high temperatures with exceptionally short habitation times.

Quick pyrolysis (all the more precisely characterized as thermolysis) is a procedure in which a material, for example, biomass, is quickly warmed to high temperatures without oxygen.

Streak pyrolysis of biomass is the thermo-compound procedure that changes over little dried biomass particles into a fluid fuel (bio-oil or bio-unrefined) for practically $75 \%$, and roast and non-condensable gases by warming the biomass to $775 \mathrm{~K}$ without oxygen. Roast in the vapor stage catalyzes auxiliary splitting. The biomass pyrolysis is an appealing alternative since strong biomass and squanders can be promptly changed over into fluid items. These fluids, as unrefined bio-oil or slurry of burn of water or oil, have favorable circumstances in transport, stockpiling, ignition, retrofitting and adaptability underway and promoting. Fast warming and quick extinguishing delivered the middle of the road pyrolysis fluid items, which gather before further responses stall higher-atomic weight species into vaporous items. High response rates limit burn development. At higher quick pyrolysis temperatures, the significant item is gas. In the event that the design is to expand the yield of fluid items coming about because of biomass pyrolysis, low temperature, high warming rate, short gas living arrangement time procedure would be required. For a high scorch creation, a low temperature, low warming rate procedure would be picked. On the off chance that the design were to expand the yield of fuel gas coming about because of pyrolysis, a high temperature, low warming rate, long gas living arrangement time procedure would be favoured.

Biomass pyrolysis finds an immediate application in power age application in Indian situation. A customary course for power age from biomass, being polished in India is immediate burning of biomass to create steam to run the turbines. The ongoing endeavours to enhance the efficiencies and to diminish the working costs, prompted the improvement of the gasoliers on the transformation side, and utilize the joined cycle and motors on the gasification side. The pyrolysis has risen out another effective course for transformation of biomass to fluids gases, and roast with fluids being the principle target. Power age utilizing this innovation is basically by the utilization of pyrolysis oils for gas turbine coordinated into a consolidated cycle.

Biomass vitality and cogeneration program is being executed with the fundamental goal of advancing advances for ideal utilization of nation's biomass assets and the misuse of the biomass control age potential, evaluated at 25,000 MW according to MNES yearly report for 2008- 09. Amid the year, biomass control/bagasse cogeneration limit expansion of 345 MW (97 MW biomass ventures and 248 MW bagasse cogeneration ventures) was accomplished in the States of Andhra Pradesh, Chhattisgarh, Karnataka, Maharashtra, Rajasthan, Tamil Nadu and Uttar Pradesh against an objective of $300 \mathrm{MW}$. The combined biomass control/bagasse cogeneration based power limit has achieved $1752 \mathrm{MW}$, which includes $703 \mathrm{MW}$ of biomass control ventures and 1049 MW of bagasse cogeneration ventures.

A portion of the cogeneration ventures have been accounted for by creators is in Southern and Eastern parts of India. Biomass gasification power age has been introduced for the two smaller than expected matrix rustic jolt and supply for fundamental framework. There is $1 \mathrm{MW}$ limit of $100 \%$ maker gas based framework associated power age was dispatched in December 2004. This is worked by Arashi Hi-Tech Bio-Power Pvt. Ltd. in Coimbatore, Tamil Nadu State as free power maker (IPP). They began the task in 2002 utilizing duel fuel motors however motors are supplanted with $4250 \mathrm{~kW}$ Cummins maker gas motors and an extra gasifier. As of now Juliflora (Prosopis juliflora) wood is utilized as the feedstock and the framework has just been worked more than $4000 \mathrm{~h}$. Juliflora is normal vegetable woody weed in the state. There are numerous different sizes of biomass gasifier country charge conspire appointed. Gosaba Island venture is the most seasoned generally substantial scale $(500 \mathrm{~kW})$ conspire and has been working since 1997. The $4250 \mathrm{~kW}$ (1 MW) establishment in Khtrichera, Tripura State would be the 


\section{International Journal of Engineering Applied Sciences and Technology, 2019 Vol. 4, Issue 6, ISSN No. 2455-2143, Pages 57-65 \\ Published Online October 2019 in IJEAST (http://www.ijeast.com)}

biggest biomass gasifier country jolt venture. Sponsorships for rustic jolt appropriation for biomass gasification country zap fluctuate contingent upon the plant limit, proprietorship and area. If there should be an occurrence of country charge possessed by network, up to $90 \%$ of absolute starting expense would be bolstered by national government and the rest can be met by network or provincial government.

\subsection{Bio-substance changes_anaerobic assimilation or maturation}

The procedure of bio-substance change of biomass did by alcoholic maturation to deliver fluid energizes and anaerobic processing or aging, for creating biogas. High dampness herbaceous plants (vegetables, sugar stick, sugar beet, corn, sorghum, and cotton) marine harvests and fertilizer are most appropriate for anaerobic assimilation. Middle of the road heat gas is methane blended with $\mathrm{CO}$ and CO2. Methane (high-heat gas) can be effectively changed over into methanol. Biogas has risen as a vital part of the sustainable power source projects of a few creating nations. Be that as it may, the spread of biogas innovation has not been proportionate with its potential.

Chanakya et al. has assessed the biomethanation of herbaceous biomass feedstock as a potential wellspring of clean vitality source in Indian situation for cooking and different exercises in regions where such biomass accessibility prevails. A biomethanation idea that includes aging of biomass build-ups in three stages, happening in three zones of the fermentor has been portrayed. As per them, India has worked around 4 million family measured biogas plants previously (out of the conceivable 12 million) that work generally with creature excreta as the sole feedstock. There are around 100 million country families in India. The objective of giving clean cooking vitality to the huge rustic populace through biogas innovation must be met by utilizing non-manure biomass feed-stocks as elective feed-stocks. Towards this mission an expansive number of lab and pilot plant contemplates have been completed at better places in India to change over different biomass feed-stocks to biogas, strikingly with water weeds, for example, water hyacinth (Eichhornia sp.) and Salvinia. The methodology had been straightforward - to pummel these feed-stocks into little particles and render them into water-based slurry lastly feed them to regular creature squander type biogas plants. Comparative endeavours have been made with kitchensquanders, crop build-ups, for example, rice straw, earthbound weeds, oceanic weeds, green growth, and so on.

Pounded water hyacinth when bolstered to a run of the mill drifting drum-type biogas plant was found to isolate into three clear zones. Chanakya et al. 2009 have announced that over $85 \%$ of the material nourished to the $12 \mathrm{~m} 3$ plant stayed above water as rubbish. This coasting rubbish involved gas storage room under the skimming gas-holder. A plainly extensive fluid zone stayed as a middle of the road layer involving $80 \%$ of digester space while a little layer of slime settled down. No processed issue left the outlet after $180 \mathrm{~d}$ activity. This methodology while endeavoring exploit multistage reactors disentangles the reactor activity and hinders the requirement for a high level of procedure control or complex reactor plan. Deteriorating herbaceous biomass discharges vast amounts of transitional unstable unsaturated fats (VFA) which will in general gather and restrain methanogenesis. Common herbaceous biomass disintegrate with a quick VFA transition at first (with an inclination to glide) trailed by a slower deterioration indicating adjusted procedure of VFA age and its use by methanogens that colonize biomass gradually. The propensity to glide at the underlying stages is smothered by permitting earlier days feed to hold it underneath digester fluid which licenses VFA to scatter into the digester fluid without causing process restraint.

This methodology has been utilized to assemble and work basic biomass digesters to furnish cooking gas in provincial regions with weed and agro-build-ups. With fitting changes, a similar idea has been utilized for processing metropolitan strong squanders in residential areas where expansive fomenters are not practical. With further changes this idea has been utilized for solid- fluid feed fomenters. Methanogen colonized leaf biomass has been utilized as bio-film backing to treat espresso handling wastewater just as harvest litter then again in a year. Amid summer it works as a biomass based biogas plants working in the three-zone mode while in winter, nourishing biomass is suspended and high quality espresso preparing wastewater is let into the ferment or accomplishing over $90 \%$ BOD decrease.

Indian principles administering MSW treatment grant just organic strategies, for example, fertilizing the soil or biomethanation for the age capable portion. While vast urban areas in India approach complex aging innovations, residential communities in the scope of 50,000- 500,000 populace bringing about USW gathering in the scope of 10- 100 t/day (accessible segment 5- 50 tons) don't approach a reasonable innovation. Normally these urban neighbourhood bodies are money starved and think that its hard to discover funds for accumulation and handling. Change to biogas (available to be purchased), manure or vermin compost gives great incomes that can coordinate the gathering and working expenses. Pilot plants of $1-2$ t/day have been worked in three towns and primer preliminaries were empowering.

\subsection{Compound change-bio-diesel from different sources}

A diesel fuel has a basic capacity in the modern economy of a creating nation and is utilized in transports, mechanical and horticultural products, and so forth. Contrasted with whatever remains of the world, India's interest for diesel powers is multiple times that of fuel. The utilization of diesel powers in India in 1994- 1995 was 28.30 million tons of diesel and 47.56 million tons of diesel in 2006-2007, which was $39.8 \%$ of the all out utilization of oil based commodities. Financial 


\section{International Journal of Engineering Applied Sciences and Technology, 2019 Vol. 4, Issue 6, ISSN No. 2455-2143, Pages 57-65 \\ Published Online October 2019 in IJEAST (http://www.ijeast.com)}

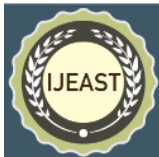

development is constantly joined by similar increment in the vehicle. This has animated the ongoing enthusiasm for elective hotspots for oil based fills. An elective fuel ought to be effectively accessible, condition inviting and technomonetarily aggressive. One of such fills is triglycerides and their subsidiaries. Vegetable oils, being inexhaustible, are generally accessible from an assortment of sources and have low sulphur substance near zero and henceforth cause less natural harm (lower green house impact) than diesel. Artificially the oils comprise of triglyceride particles of three long chains unsaturated fats that are ester attached to a solitary glycerol atom. These unsaturated fats vary by the length of carbon chain, introduction and position of twofold securities in these chains. In this manner bio-diesel alludes to bring down alkyl esters of long chain unsaturated fats, which are combined either by stupors check with lower alcohols or by etherification of unsaturated fats.

The utilization of vegetable oils, for example, soya-bean, palm, sunflower, shelled nut and olive oil as elective fuel has been around for a long time when the innovator of the diesel motor Rudolph Diesel originally tried nut oil, in his pressure start motor. Diverse nations are searching for various sorts of vegetable oils as substitutes for diesel powers that relying on the atmosphere and soil conditions. For instance, soya-bean oil in U.S., rapeseed and sunflower oils in Europe, palm oil in Southeast Asia and coconut oil in Philippines are being utilized. The utilization of vegetable oils as wellsprings of diesel would require more endeavours to expand the generation of oil seed and to grow new and progressively gainful plant species with high return of oil, furthermore, a few types of plants yielding non-eatable oils.

The arranging commission of India has propelled a biofuel venture in 200 locale of the 18 states in India. It has prescribed two plant species viz. (Jatropha curcas) and Karanj (Pungamia pinnata) for bio-diesel creation. Both these plants might be developed on a gigantic scale on horticultural/corrupted/squander lands, with the goal that the central asset might be accessible to create bio-diesel on 'ranch scale'. Vegetable oils involve a conspicuous position in the advancement of elective powers despite the fact that, there have been numerous issues related with utilizing it specifically in diesel motor. These incorporate obstruction of high consistency of vegetable oil with the infusion procedure prompting poor fuel atomization, wasteful blending of oil with air bringing about fragmented burning and high smoke outflow, lube oil weakening, high carbon stores, ring staying, scraping of the motor liner, and Injection spout disappointment. Then again, high glimmer guide traits toward lower instability qualities. Their failure to be ordered into sorts and grade of oil and neighbourhood climatic conditions are alternate elements for their unacceptability. For these triglycerides, both cloud and pour focuses are altogether higher than that of diesel fuel. These high qualities may cause issues amid virus climate. These issues are related with vast triglycerides particle and its higher sub-atomic mass, which is maintained a strategic distance from by synthetically adjusted to vegetable oil in to bio-diesel that is comparable in qualities of diesel fuel.

The response to these issues was found in compound transformation of these triglycerides or vegetable oils were found in their concoction change to the bio-diesel by transesterification. The transesterification is an imperative procedure to create the cleaner and earth safe fuel from vegetable oils. Bio-diesel is characterized as the mono alkyl esters of long chain unsaturated fats got from sustainable feed stock, for example, vegetable oil or creature fats, for use in pressure start motors. Bio-diesel which is considered as a conceivable substitute of ordinary diesel fuel is ordinarily made out of unsaturated fat methyl/ethyl esters, acquired from triglycerides by transesterification with methanol/ethanol individually. Bio-diesel is perfect with ordinary diesel and both can be mixed in any extent.

In proceeded with endeavours for expanding financial practicality of producing bio-diesels from different consumable, non-palatable and squander oils; another idea has picked up the energy in later past. This is generation of biodiesel from green growth. Prior investigations on fluid fuel from microalgae had started in mid-1980s. Amid the world war II, albeit some German researchers endeavoured to separate lipids from diatom so as to determine vitality emergency, and soon later in the USA, look into was directed by a gathering of researchers at the Carnegie Institution of Washington, and their encounters had been outlined in a book entitled "Algal Culture from Laboratory to Pilot Plant", however the advancements of making microalgae as powers had not been completely abused. The reasons could be as per the following. First reason is that microalgae are less known wellspring of lipids than plants and creatures. Second, the costs for most plant oils are generally low and creature fats are significantly less expensive; in this way, forms for the microbial oils generation

Khan et al. has introduced a basic assessment on prospects of bio-diesel generation microalgae. They have underscored the need to investigate the conceivable outcomes of delivering bio-diesel from microalgae, as it won't rival the land and grain crops. In India, around 26 million hectare lands are utilized for the oilseed development, for the most part on non-watered peripheral terrains, subject to storm downpours, and with low dimensions of info use. With the outcome, the yields of oilseeds development are preferably low at less over $1 \mathrm{t} / \mathrm{ha}$. Then again, in India, per capita utilization of palatable oil is likewise developing consistently with enduring development in populace and individual salary. This is despite the way that Indian vegetable oil economy is world's fourth biggest after USA, China and Brazil. In any case, oilseeds yield and thus, vegetable oil generation have been trailing utilization development, requiring imports to meet supply setback. 


\section{International Journal of Engineering Applied Sciences and Technology, 2019 Vol. 4, Issue 6, ISSN No. 2455-2143, Pages 57-65 \\ Published Online October 2019 in IJEAST (http://www.ijeast.com)}

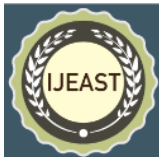

In this way, for nation like India, which as of now relies upon the imports of vegetable oil, we need to see alternate choices for financially practical creation of bio-diesel. Since the interest for consumable vegetable oil surpasses supply, the administration chose to utilize non-eatable oil from $\mathbf{J}$. curcas oilseeds as bio-diesel feedstock. Be that as it may, the principle issue in making history is the trouble connected to starting vast scale development of Jatropha. Ranchers don't yet consider Jatropha development sufficiently gainful in light of the fact that the organic products show up following 3 years of yield manor. For example, sugarcane ranches yield 70 t/ha and get the agriculturist Rs. 70,000/ha at a sugarcane cost of Rs. 1000/t. In correlation, the Jatropha rancher gets Rs. 5000/t of oilseeds and if the yield is $3.75 \mathrm{t} / \mathrm{ha}$, his pay will be just Rs. $18,750 /$ ha [86]. The other principle issue is the absence of seed accumulation and oil extraction foundation. Without this framework and accessible oilseeds, it will be hard to convince business people to introduce transesterification plants.

In perspective on the abovementioned, in the case of being eatable oil or non-consumable oil, we are not getting the feasible option of bio-diesel. There is a pressing need to configuration coordinated vitality cultivates that are equipped for creating fuel and manures other than nourishments and feed. These vitality ranches ought to be set up on waste/fruitless grounds and should require least assets like crisp water or compound manures. Today, the potential estimation of micro algal photosynthesis to create bio-diesel is, in any case, generally perceived. Generation of bio-diesel utilizing microalgae biomass seems, by all accounts, to be a feasible option. The oil profitability of numerous microalgae surpasses the best creating oil crops. Microalgae are photosynthetic microorganisms which convert daylight, water and $\mathrm{CO} 2$ to sugars, from which macromolecules; for example, lipids and triacylglycerols (TAGs) can be acquired. These TAGs are the promising and practical feedstock for bio-diesel generation. Micro algal bio-refinery approach can be utilized to decrease the expense of making micro algal bio-diesel. Small scale algal-based carbon sequestration advances spread the expense of carbon catch and sequestration. Along these lines, the street ahead for India is to see the reasonable choice of algal cultivating.

\section{CONCLUSION}

A basic investigation of the capability of biomass transformation to vitality has been exhibited. It is obvious from the above talks that a vast potential lies for the abuse of accessible biomass in India to change over it to vitality. Vast extension exists for the warm transformation procedures, for example, pyrolysis, liquefaction and biomass gasification for power age in India. In perspective on the accessibility of waste biomass for example horticultural waste, sustenance squanders, modern wastewaters created in expansive volumes, and MSW, anaerobic assimilation is a promising course.
Various power age ventures are as of now demonstrated effective in India dependent on gasification based cogeneration rustic jolt plants. These plants have not just tackled the country charge issue for the remote towns, where infrastructural expenses could have been very high for ordinary jolt, yet additionally the power age cost has likewise been moderately low. Creation of bio-oils by quick pyrolysis likewise can be very practical, for power age applications, with specific imperatives, not extremely hard to survive.

In the event that we discuss second era powers, the characteristic challenge with nourishment crops, just as GHG creation because of land-use change and transportation of bioyields to the bio-refineries, may represent a few obstacles in the method for bio-diesel generation. Be that as it may, it may not be hard to defeat it with certain therapeutic estimates, for example, setting bio-refineries in close region of the bio-crop creation fields. In present day situation, non-palatable oils likewise don't appear to offer exceptionally appealing alternatives because of constrained accessibility of minimal terrains just as less gainful endeavour for agriculturists. The arrangement might be found in the green growth based biodiesel generation. With unfaltering upward interest for the oil based fills, and steady increment popular of electrical power age, it appears that warm change forms just as cogeneration based gas control plants may rise out as an answer for the vitality issue of India.

\section{REFERENCE}

[1] Andersson J, Bjornsson L. Evaluation of straw as a biofilm carrier in the methanogenic stage of two-stage anaerobic digestion of crop residues. Bior-esour Technol 2002; 85:51-6.

[2] Appel HR, Fu YC, Friedman S, Yavorsky PM, Wender I. Converting organic wastes to oil. US Burea of Mines Report of Investigation No. 7560; 1971.

[3] Bhat PR, Chanakya HN, Ravindranath NH. Biogas plant dissemination: success story of Sirsi, India. Energy Sustain Dev 2001; V(March (1)):39-41.

[4] Bhattacharya SC, Jana C. Renewable energy in India: historical developments and prospects. Energy 2009;34:981-91.

[5] Buragohain B, Mahanta P, Moholkar Vijayanand S. Biomass gasification for decentralized power generation: the Indian perspective. Renew Sust Energy Rev 2010;14(January (1)):73-92.

[6] Chanakya HN, Reddy BVV, Modak J. Biomethanation of herbaceous biomass residues using 3-zone plug flow like digesters - a case study from India. Renew Energy 2009; 34: 416-20.

[7] Davies E. The biofuel future?In: Chemistry World; April 2009. p. 40-43. 
[8] Demirbas A. Biofuels securing the planet's future energy needs. Energy Conversion Manage 2009;50:2239-49.

[9] Ganesh A, Banerjee R. Biomass pyrolysis for power generation-a potential technology. Renew Energy 2001;22:9-14.

[10] Basic statistics on Indian Petroleum \& Natural Gas. Ministry of Petroleum and Natural Gas, Economic Division; 2008-09, http://petroleum.nic.in/total.pdf.

[11] CES. Annual report. Bangalore: Centre for Ecological Sciences, IISc; 1995.

[12] CMIE. Directory of Indian agriculture, Mumbai, India; 1997.

[13] Handbook of statistics: section A, Table 03. India: Ministry of Agriculture; 1996-97, http://dacnet.nic.in/rice/HS-A-Table-03.htm.

[14] http://www.bioenergywiki.net/Main_Page. 